\title{
Water relations and an expression analysis of plasma membrane intrinsic proteins in sensitive and tolerant rice during chilling and recovery
}

\author{
Xin Yu ${ }^{1}$, Yan Hui Peng ${ }^{1}$, Min Hua Zhang ${ }^{1}$, Yan Jun Shao ${ }^{1,2}$, Wei Ai Su${ }^{1}$, Zhang Cheng Tang ${ }^{1}$ \\ ${ }^{1}$ Institute of Plant Physiology and Ecology, Shanghai Institutes for Biological Sciences, Chinese Academy of Sciences, 300 Fenglin \\ Road, Shanghai, 200032, China; ${ }^{2}$ Life Science College, Hebei Agriculture University, 38 Ling-Yu-Si street, Baoding, Hebei, 071001, \\ China
}

A symptom of chilling injury is development of water deficit in shoots, resulting from an imbalance of water transport and transpiration. In this work, two rice varieties (Oryza sativa L. var. Wasetoitsu and Somewake) seedlings were chilled at $7{ }^{\circ} \mathrm{C}$, followed by recovery at $28^{\circ} \mathrm{C}$. Based on the growth phenotype and electrolyte leakage tests, Somewake was shown to be a chilling-tolerant variety, and Wasetoitsu a chilling-sensitive one. The chilling stress reduced markedly the relative water content (RWC) of leaves, accumulative transpiration and osmotic root hydraulic conductivity (Lp) in both varieties. But when returned to $28^{\circ} \mathrm{C}$, the water relation balance of Somewake recovered better. The mRNA expression profile of all the 11 plasma membrane intrinsic proteins (PIPs), a subgroup of aquaporins, was subsequently determined by real-time reverse transcription (RT)-PCR with TaqMan-minor grove binder (MGB) probes derived from rice var. Nipponbare during chilling treatment and recovery. Most of the PIP genes was down-regulated at the low temperature, and recovered at the warm temperature. The relative expression of some PIPS in both Somewake and Wasetoitsu decreased in parallel during the chilling. However during the recovery, the relative expression of OsPIP $1 ; 1$, OsPIP2;1, OsPIP 2;7 in shoots and $O_{s} P I P 1 ; 1, O_{s} P I P 2 ; 1$ in roots were significantly higher in Somewake than Wasetoitsu. This supports the role of PIPs in re-establishing water balance after chilling conditions. We discuss the diversified roles played by members of the aquaporin PIP subfamily in plant chilling tolerance depending on aquaporin isoforms, plant tissue and the stage of chilling duration.

Cell Research (2006) 16:599-608. doi:10.1038/sj.cr.7310077; published online 15 June 2006

Keywords: aquaporin, chilling, gene expression, plasma membrane intrinsic protein, rice

\section{Introduction}

Chilling to non-freezing temperature is detrimental to plant growth and development, and consequently decreases the productivity of crops. Tremendous efforts over several decades have been made to understand the mechanisms underlying plant responses to chilling [1]. Many reports have emphasized the changes in water relations because water

Correspondence: Wei Ai Su

Tel: 86-21-54924245; Fax: 86-21-54924015;

E-mail: zstressc@online.sh.cn

Received 1 Sep 2005; revised 25 Oct 2005; accepted 26 Dec 2005; published online 15 Jun 2006 homeostasis is essential for plant survival under this stress condition, and a significant symptom of chilling injury is shoot water deficit resulting from imbalance between water transport and transpiration [2]. It has been well documented that root water transport is sharply suppressed by exposure to low temperature in a number of species, including maize [3-6], rice [7], bean [8], spinach [9], aspen [10], cucumber and figleaf gourd $[11,12]$. Some studies have also demonstrated that a decrease in transpiration follows the reduction in root water flow $[5,10]$.

The concept that water flux across membranes is facilitated by aquaporins provides a new insight into plant water relations [13-16]. The relationship between aquaporins and plant chilling tolerance is an intriguing question with great 
agricultural significance. The composite water transport model proposes that water channels play a role in cell-tocell water flow under adverse environmental conditions when low transpiration and xylem tension occurs $[17,18]$. Aquaporins have previously been reported to be involved in chilling responses $[4,19]$ but only recently have comprehensive analysis of aquaporin expression at the mRNA level in response to low temperature been done. Techniques used were Northern blot, semi-quantitative reverse transcription (RT)-PCR and real-time RT-PCR using SYBR green dye in species such as Arabidopsis [20], maize [6] and rice [7]. Comparative analysis between cucumber (chilling sensitive) and figleaf gourd (chilling resistant) indicated that the decrease in cell hydraulic conductivity (Lp) at low temperature was associated with the open/close state of water channels $[11,12]$. However, in chilling-sensitive maize, the decrease in root Lp upon chilling was due to oxidative damage to the membranes rather than a decrease in aquaporin amount or a change in phosphorylation status [6]. The roles of aquaporins in plant chilling tolerance remain elusive.

In order to gain insight into the integrated roles of aquaporins in response to stress, it is necessary to investigate the overall expression of the aquaporin family under stress conditions. Aquaporins belong to a large and highly conserved family of major intrinsic proteins (MIP) [21, 22]. For instance, 35 and 31 members of MIPs have been predicted or identified in Arabidopsis [23] and maize [24], respectively. MIPs can be classified into 4 subfamilies including plasma membrane intrinsic protein (PIP), tonoplast intrinsic protein (TIP), NOD26-like intrinsic protein (NIP) and small basic intrinsic protein (SIP). The recently developed technique of real-time RT-PCR using TaqMan- minor grove binder (MGB) probe, which has high specificity and sensitivity [25], provides a powerful tool for quantitatively investigating the overall expression of gene families with many members sharing high homology, such as the plant MIP family.

In this paper, we focused our efforts on the roles of rice PIPs in chilling tolerance. Rice seedlings were chilled at low temperature $\left(7^{\circ} \mathrm{C}\right)$, followed by recovery at $28^{\circ} \mathrm{C}$. The water relations of two rice varieties, Somewake and Wasetoitsu that are chilling tolerant and sensitive, respectively were initially compared during chilling and recovery. In order to investigate the integrated expression of the gene family encoding PIP in rice by real-time RT-PCR, genes encoding for PIPs in var. Nipponbare were surveyed. Sakurai et al. [7] recently reported the identification of 33 rice aquaporin genes (11 PIPs, 10 TIPs, 10 NIPs and 2 SIPs) by analysis of the rice genome. Hence, throughout this paper, we have used the aquaporin names as proposed by Sakurai et al. [7]. We selected 4 PIP genes including 3 coding for functional water channel proteins (OSPIP $1 ; 1$, OsPIP2;1 and $O s P I P 2 ; 7)$ and a root-specific one $(O s P I P 2 ; 3)$ for comparing the transcript expression level of Somewake and Wasetoitsu during chilling and recovery. We attempted to unravel the roles of PIP aquaporins in plant chilling tolerance by matching the differences in water relations of the two varieties with the PIPs expression during chilling treatment.

\section{Materials and Methods}

\section{Plant materials and growth condition}

We were able to use information from the recently completed rice genome sequencing project based on Oryza sativa L. var. Nipponbare to investigate mRNA expression of all 11 PIPs in response to chilling. Two rice varieties were used, Wasetoitsu, a chilling sensitive variety developed in the Republic of Korea, and Somewake, a chilling tolerant variety developed in Japan. Seeds were germinated for 2-3 d at 28 ${ }^{\circ} \mathrm{C}$ in the dark on filter paper soaked with distilled water. Afterwards, the seedlings were grown hydroponically in nutrient solution [26] at photon flux density of $350-400 \mu \mathrm{mol} \mathrm{m} \mathrm{m}^{-2} \mathrm{~s}^{-1} \mathrm{PAR}, 60-80 \%$ relative humidity, $12 \mathrm{~h} / 12 \mathrm{~h}$ day-night cycle at $28{ }^{\circ} \mathrm{C}$ in a phytotron.

\section{Low temperature treatment and recovery}

Thirty-five-day-old rice seedlings were moved from the phytotron to a growth chamber $\left(28^{\circ} \mathrm{C}\right.$ air temperature, $60-70 \%$ relative humidity and light density of $200 \mu \mathrm{mol} \mathrm{m} \mathrm{m}^{-2} \mathrm{~s}^{-1} \mathrm{PAR}$ with $12 \mathrm{~h}$ photoperiod) for $2 \mathrm{~d}$ before the chilling treatment. The $7{ }^{\circ} \mathrm{C}$ chilling treatment was carried out by exposure to cool air and started $1 \mathrm{~h}$ after the beginning of illumination. The temperature was returned to $28{ }^{\circ} \mathrm{C}$ after $24 \mathrm{~h}$ of the chilling treatment and the plants was allowed to recover for $24 \mathrm{~h}$. Low irradiance $\left(200 \mu \mathrm{mol} \mathrm{m} \mathrm{m}^{-2}\right.$ PAR) was used to avoid photo-oxidation damage during chilling and to focus our study on low temperature effects on water relations per se.

\section{Electrolyte leakage test}

Washed leaves $(0.2 \mathrm{~g})$ were cut into $1 \mathrm{~cm}$ slices and put in a test tube containing $5 \mathrm{~mL}$ of deionized water. The leaf samples were immersed and vibrated occasionally at $25^{\circ} \mathrm{C}$ for $2 \mathrm{~h}$, and then the electrical conductivity of the solution $(\mathrm{C} 1)$ was measured using a conductivity meter. After boiling the samples for $10 \mathrm{~min}$, their conductivity $(\mathrm{C} 2)$ was measured again after the solution was cooled to room temperature. The relative electrical conductivity (REC) was calculated as follows:

$$
\operatorname{REC}(\%)=\mathrm{C} 1 / \mathrm{C} 2 \times 100
$$

\section{Relative water content ( $R W C$ ) measurement}

Rice leaves were collected and immediately weighed to determine their fresh weight (FW). Leaves were then transferred to sealed plates and hydrated between two pieces of filter paper, which were drenched in deionized water. After $10 \mathrm{~h}$ of hydration at $4^{\circ} \mathrm{C}$, the leaf surface was blotted dry, and the turgid weight (TW) recorded. Leaf samples were then oven dried at $80^{\circ} \mathrm{C}$ for $24 \mathrm{~h}$ and the dry weigh (DW) determined. The RWC was calculated via the following equation:

$$
\mathrm{RWC}(\%)=\frac{\mathrm{FW}-\mathrm{DW}}{\mathrm{TW}-\mathrm{DW}} \times 100
$$




\section{Accumulative transpiration}

Accumulative transpiration was measured as described in a previous report [27]. The weight of tubes and liquid medium in which rice seedlings grew was measured and the moisture lost was replenished every $3 \mathrm{~h}$. Moisture loss per hour on the basis of leaf dry weight was described as the accumulative transpiration.

Osmotic root hydraulic conductivity (Lp) measurement

The osmotic root Lp was measured essentially based on the method described by Miyamoto et al. [28] and Martinez-Ballesta et al. [29]. In brief, seedling shoots were excised with a razor blade $10-20 \mathrm{~mm}$ from the base, and the exuded sap was collected with a micropipette and the flow rate $\left(\mathrm{J}_{\mathrm{v}}\right)$ on a root dry mass basis measured over the next $90 \mathrm{~min}$. The osmotic potential of bath medium $\left(\Pi_{\mathrm{b}}\right)$ and sap $\left(\Pi_{\mathrm{s}}\right)$ exuded from individual plants were measured by a Vapor Pressure Osmometer (Wescor, USA). The osmotic root Lp was calculated from the following equation:

$$
\mathrm{Lp}=\mathrm{J}_{\mathrm{v}} /\left[\sigma \cdot\left(\Pi_{\mathrm{b}}-\Pi_{\mathrm{s}}\right)\right]
$$

In this equation, $\sigma$ was the root reflection coefficient for nutrient salts in the xylem and was estimated to be $\sigma=0.4$ [28].
Extraction of RNA and first strand $c D N A$ synthesis

Total RNA was extracted from roots and shoots using RNArose reagent (Watson, China). The residual genomic DNA was removed by DNA-free ${ }^{\mathrm{TM}} \mathrm{Kit}$ (Ambion, USA). The concentration of RNA was accurately quantified by spectrophotometric measurement. The cDNA was synthesized using oligo $(\mathrm{dT})_{18}$ primer and ReverTra Ace M-MLV RTase (Toyobo, Japan) in a total volume of $20 \mu \mathrm{L}$ according to the manufacturer recommendation. The cDNA mixtures were diluted to $120 \mu \mathrm{L}$ with sterile $\mathrm{ddH}_{2} \mathrm{O}$ and $2.5 \mu \mathrm{L}$ were used as template for real-time PCR in a total volume of $20 \mu \mathrm{L}$.

\section{Primers and TaqMan-MGB probes}

The primers and TaqMan-MGB probes were designed using Primer Express 2.0 software (Applied Biosystems-Perkin-Elmer, USA) based on the sequences of rice PIP genes from Nipponbare. Ubiquitin (UBI) (NCBI accession number D12629) was used as the internal control. The sequence of PCR primers and TaqMan-MGB probes are shown in Table 1. All the primers and probes were synthesized by Shanghai GeneCore Company (Shanghai, China). The

Table 1 Primers and TaqMan-MGB probes for real-time RT-PCR

\begin{tabular}{|c|c|c|c|c|}
\hline Name & Synonymy & Access & Probe & Primer \\
\hline OsPIP1;1 & $R W C 1 / P I P 1 a$ & AK061769 & TGTAGTTGCCAGTGGCT & $\begin{array}{ll}\mathrm{F} & \text { TACATGGGCAATGGCGGT } \\
\mathrm{R} & \mathrm{CAAGACCGTCACCCTTGGTG}\end{array}$ \\
\hline OsPIP $1 ; 2$ & & AK098849 & ACCGTCCTCACCGTCAT & $\begin{array}{ll}\text { F } & \text { GGCCACCTTCCTCTTCCTTTAC } \\
\text { R } & \text { GCGCACTTGGAGGTGGAGT }\end{array}$ \\
\hline OsPIP $1 ; 3$ & $R W C 3$ & AK102174 & СТCСТCCACCTCGAACA & $\begin{array}{l}\text { F AAGGACTACCGGGAGCCG } \\
\text { R } \text { GGTAGAACGACCACGACGTCA }\end{array}$ \\
\hline OsPIP $2 ; 1$ & $P I P 2 a$ & AK072519 & TCGGCCTCGTCAAGG & $\begin{array}{ll}\text { F } & \text { AGTGCCTCGGCGCCAT } \\
\text { R } & \text { CGTACCTGTTGAAGTAGGCGCT }\end{array}$ \\
\hline OsPIP $2 ; 2$ & & AK061782 & CTGATCAGGGCGGTGC $^{\text {a }}$ & $\begin{array}{ll}\text { F } & \text { TTCGGGCTGTTCCTGGC } \\
\text { R } & \text { GGCACTGCGCGATGATGTA }\end{array}$ \\
\hline OsPIP $2 ; 3$ & & AL662958 & AAGAGGAGCAAGCACGG & $\begin{array}{ll}\mathrm{F} & \text { TCTTCTCCGCCACCGACC } \\
\mathrm{R} & \text { AACACCGCGAACCCAATTG }\end{array}$ \\
\hline OsPIP $2 ; 4$ & & AK072632 & ACTCACATGTTCCCGTGTT & $\begin{array}{l}\text { F ACCGATCCCAAGCGCAA } \\
\text { R GCGAACCCGATTGGCAG }\end{array}$ \\
\hline OsPIP $2 ; 5$ & & AK107700 & CGACCATCCCCGTCAC $^{a}$ & $\begin{array}{l}\text { F CCGTGTTCATGGTGCACCT } \\
\text { R CCGGGTTGATGCCGGT }\end{array}$ \\
\hline OsPIP $2 ; 6$ & & AK061312 & ACACCGTCTTCTCCGC ${ }^{\mathrm{a}}$ & $\begin{array}{l}\text { F GAAATCATCGGCACCTTCGT } \\
\text { R GGGCATTGCGCTTTGG }\end{array}$ \\
\hline OsPIP $2 ; 7$ & & AK109439 & CTGTACCGTGCCCTC & $\begin{array}{l}\text { F ACGAGCGAGCTGGGTAAGTG } \\
\text { R ATGAGCGTCGCCATGAACTC }\end{array}$ \\
\hline OsPIP $2 ; 8$ & & AK109024 & CTGCTGTTGGTGTGCAT & $\begin{array}{l}\text { F CATTGCGGAGTTCACAGCC } \\
\text { R CCGATCACGGTGCTCACA }\end{array}$ \\
\hline$U B I$ & & D12629 & CACCACAGCACACGC & $\begin{array}{l}\text { F TTGTCCTGCGCCTCCGT } \\
\text { R GGCATAGGTATAATGAAGTCCAATGC }\end{array}$ \\
\hline
\end{tabular}

${ }^{a}$ These probes were designed to span the introns of their genomic sequences.

${ }^{\mathrm{b}}$ AL662958 was genome sequence access number, and others were cDNA clone access number. 
probes were labeled with the fluorescent reporter dye 6-carboxy-fluoroscein (FAM) on the $5^{\prime}$ end, and with the fluorescent quencher dye 6-carboxytetramethylrhodamine (TAMRA) and MGB on the 3 ' end. They formed extremely stable duplexes with single-stranded DNA targets, allowing shorter probes to be designed. All PCR primers were designed to produce PCR products of about $70 \mathrm{bp}$ in length.

\section{Real-time PCR}

TaqMan-MGB real-time PCR was performed in Rotor-Gene 3000 real-time thermal cycling system (Corbett Research, Australia) using Real-time PCR Master Mix (Toyobo, Japan). The reaction mixture $(20 \mu \mathrm{L})$ contained $2.5 \mu \mathrm{L}$ of diluted cDNA, 4 pmol of each primer, 4 pmol TaqMan-MGB probe and appropriate amounts of other components as recommended by the manufacturer (Toyobo, Japan). The real-time PCR was programmed for $5 \mathrm{~min}$ at $95^{\circ} \mathrm{C} ; 50$ cycles of 20 s at $94{ }^{\circ} \mathrm{C}$ and $30 \mathrm{~s}$ at $60{ }^{\circ} \mathrm{C}$. The data were collected and analyzed with the Rotor Gene 3000 software (Corbett Research, Australia). Each sample was quantified in triplicate. For the control reactions, either no sample was added or RNA alone was added without reverse transcriptase to test if the RNA sample contained contaminating genomic DNA. The housekeeping gene $U B I$ was used as the internal standard to normalize target genes [30]. To generate standard curves for the PIPS and $U B I$, a range of ten-fold dilutions of the conventional RT-PCR products corresponding to PIP and $U B I$ were tested in the same conditions as the experimental samples.

\section{Plasma membrane protein extraction and Western blot}

Root plasma membrane fractions were prepared by the aqueous two-phase partitioning method as describe by Ohshima et al. [31]. Membrane protein concentration was measured according to Bradford [32]. Western blots were done essentially by the standard method described by Sambrook et al. [33]. Protein samples $(20 \mu \mathrm{L})$ were separated by SDS-PAGE $[12 \%(\mathrm{w} / \mathrm{w})$ acrylamide], transferred to nitrocellulose membranes and blocked with $5 \%(\mathrm{w} / \mathrm{v})$ skim milk in phosphate-buffered saline for $1 \mathrm{~h}$. Rabbit serum raised against the N-terminal conserved peptide, KDY NEP PPA PLF EPG ELS SWS, of PIP conjugated to bovine serum albumin (BSA) was used as the primary antibody $(1: 500)$ and anti-rabbit $\operatorname{IgG}(1: 1,000)$ conjugated to alkaline phosphatase as the secondary antibody. The signals were visualized by 5-bromo-4-chloro-3-indolyphsophate/nitro-blue tetrazolium (NBT/BICP) substrates.

\section{Results}

Wasetoitsu and Somewake were different in chilling tolerance

Wasetoitsu and Somewake rice varieties were used. After 6-9 h treatment at $7{ }^{\circ} \mathrm{C}$, Wasetoitsue showed obvious symptoms of chilling-induced water deficit, such as wilting, leaf rolling and drooping. However with Somewake, no obvious phenotypic change was observed except for slight leaf rolling. As a representative example, Figure 1A shows the different phenotypes of these varieties chilled at $7{ }^{\circ} \mathrm{C}$ for $24 \mathrm{~h}$. After $1 \mathrm{~h}$ of recovery at $28^{\circ} \mathrm{C}$, the leaves of Somewake had expanded completely yet leaf tips in Wasetoitsu were observed to be dry even after $24 \mathrm{~h}$ of the recovery (data not shown). The leaf REC, a key parameter of chilling injury, was increased after $6 \mathrm{~h}$ at low temperature in both varieties, but the leaf REC of Wasetoitsu was approximately 3 times higher than that of Somewake after $9 \mathrm{~h}$ of chilling (Figure 1B). These data confirmed that Wasetoitsu was a less chilling tolerant variety, which was consistent with a previous evaluation by Kitagawa and Yoshizaki [34].
A

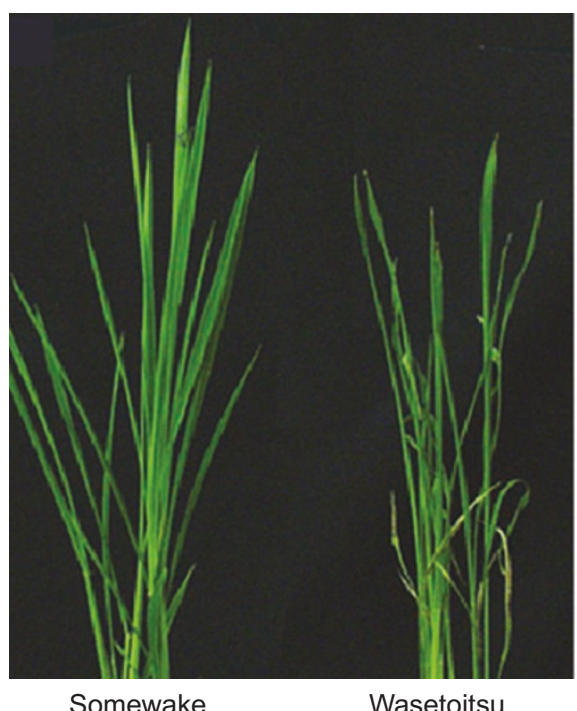

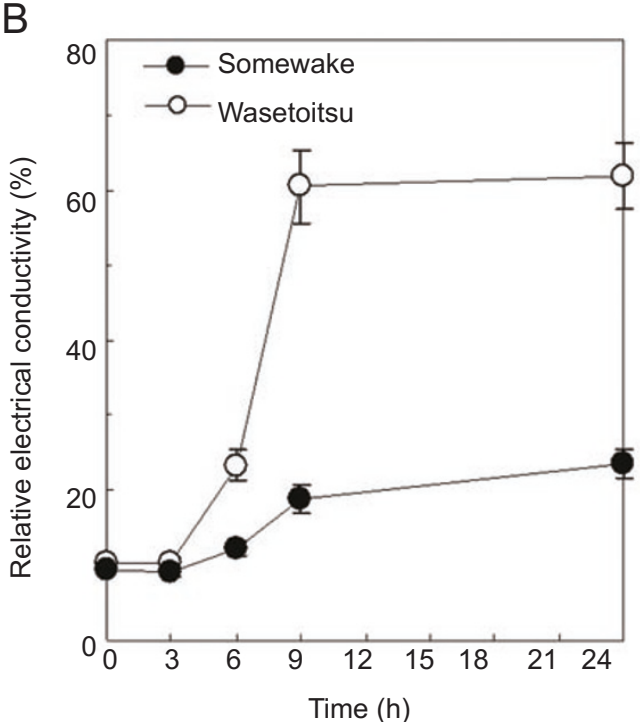

Figure 1 Different phenotypes (A) and leaf relative electrical conductivity (REC) (B) of two rice varieties differing in chilling sensitivity (Somewake, tolerant and Wasetoitsue, sensitive) when chilled at $7^{\circ} \mathrm{C}$ for $24 \mathrm{~h}$. Young leaves of Wasetoitsu were rolled, and some old leaves wilted and drooped, while no visible response was observed in Somewake (A). The data are means \pm S.D. for 5 independent samples (B). 


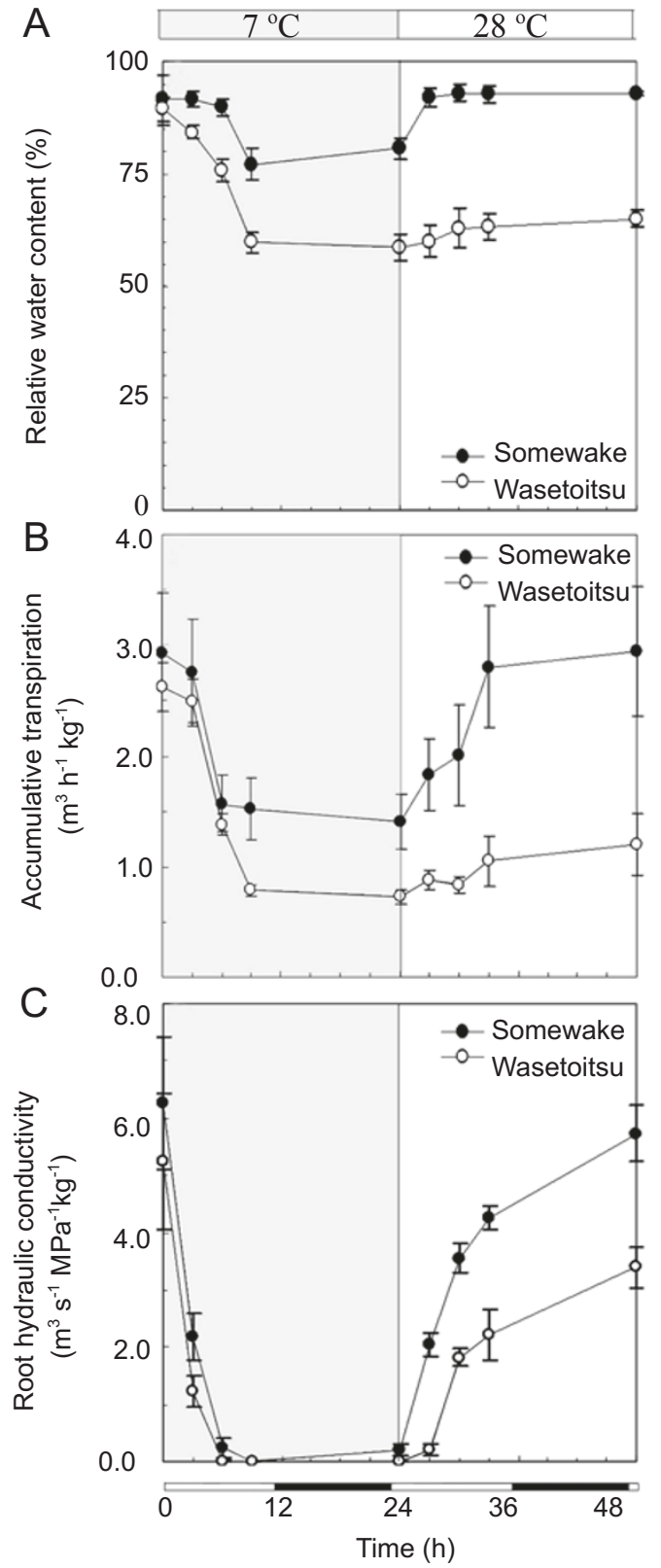

Figure 2 Relative water content (RWC) of leaves (A), accumulative transpiration (B) and root osmotic hydraulic conductivity $(\mathbf{C})$ in the rice varieties Somewake and Wasetoitsue, at low temperature $\left(7^{\circ} \mathrm{C}\right)$ (grey column) and after recovery at $28^{\circ} \mathrm{C}$ (white column). Plants were grown in a $12 \mathrm{~h}$ light (white rectangle) / $12 \mathrm{~h}$ dark (black rectangle) cycle. The data are means \pm S.D. for 5 independent samples.

Water relations in Wasetoitsu and Somewake during chilling and recovery

During the chilling and recovery, the root RWC of both varieties remained unchanged (data not shown). However, during the low temperature treatment, leaf RWC gradually declined, and Wasetoitsu had a remarkably lower leaf RWC than the Somewake (Figure 2A). The two varieties were different in extent of improvement to leaf water status during the recovery. After a recovery period of $3 \mathrm{~h}$, leaf RWC of Somewake returned to the pre-chilling level. Yet after a $24 \mathrm{~h}$ recovery period, the leaf RWC of Wasetoitsu was only $72.5 \%$ of the pre-treatment level (Figure 2A). Accumulative transpiration decreased during chilling, with a minimum, after $24 \mathrm{~h}$ of chilling, of approximately $48 \%$ and $30 \%$ of initial values for Somewake and Wasetoitsu, respectively (Figure 2B). Osmotic root Lp dropped sharply and immediately after the chilling treatment in both varieties. After $9 \mathrm{~h}$ chilling treatment, osmotic root $\mathrm{Lp}$ was too low to be detected in either variety, and only Somewake showed very slight recovery of Lp $24 \mathrm{~h}$ after warming (Figure 2C). Osmotic root Lp decreased more quickly and to a larger extent than accumulative transpiration (Figure $2 \mathrm{~B}$ and $2 \mathrm{C}$ ), suggesting the imbalance between water transport in root and water evaporation in aerial parts. This water imbalance probably resulted in the low RWC in leaves (Figure 2A). Somewake returned to more normal levels of accumulative transpiration and osmotic root Lp than Wasetoitsu, consistent with the higher leaf RWC. For instance, after $24 \mathrm{~h}$ of recovery, the accumulative transpiration and Lp of Somewake had returned to the initial values, yet for Somewake they were only $46 \%$ and $65 \%$ of initial values, respectively.

Profile of PIP gene expression in rice (var. Nipponbare) under non-stressed and chilling conditions

The ratio of $P I P / U B I$ was used to determine transcript levels of rice PIPs. The transcript levels of the 11 PIP genes, varied considerably and there were also differences between shoots and roots under non-stressed conditions (Figure 3). The OsPIP1; 1 in roots was transcribed at an extremely high level of 1.43 , much higher than the range of $10^{-2} \sim 1$ for $O S P I P 1 ; 1$ (in shoots), OsPIP 1;2, OsPIP2;1, OsPIP 2;2, and OsPIP 2;3 (in roots), OsPIP 2;4 (in roots), OsPIP2;6 and OsPIP2;7 (in shoots), which had intermediate transcript levels. A group with low expression were $O s P I P 1 ; 3$ and $O s P I P 2 ; 4$ (in shoots), OsPIP2;5 and OsPIP 2; 7 (in roots), and $O s P I P 2 ; 8$ with transcript levels ranging from $10^{-5} \sim 10^{-2}$. OsPIP2;3 was only expressed in roots and barely detected in shoots, therefore, OSPIP $2 ; 3$ in shoots was omitted in Figure 3 and Figure 4.

Rice PIPs in control plants had large fluctuations in expression during a light/dark cycle (data not shown) confirming a previous report [7]. Thus we compared the changes in expression of all 11 PIPs in concurrent control plants without chilling treatment to the chilled plants both during chilling and after recovery. The relative expression level was defined as the ratio of treatment/concurrent control. As shown in Figure 3, the chilling treatment resulted in a sharp decrease in relative expression of most PIPs in both shoots 
\begin{tabular}{l}
$A$ \\
0 \\
0 \\
5 \\
5 \\
\hline
\end{tabular}

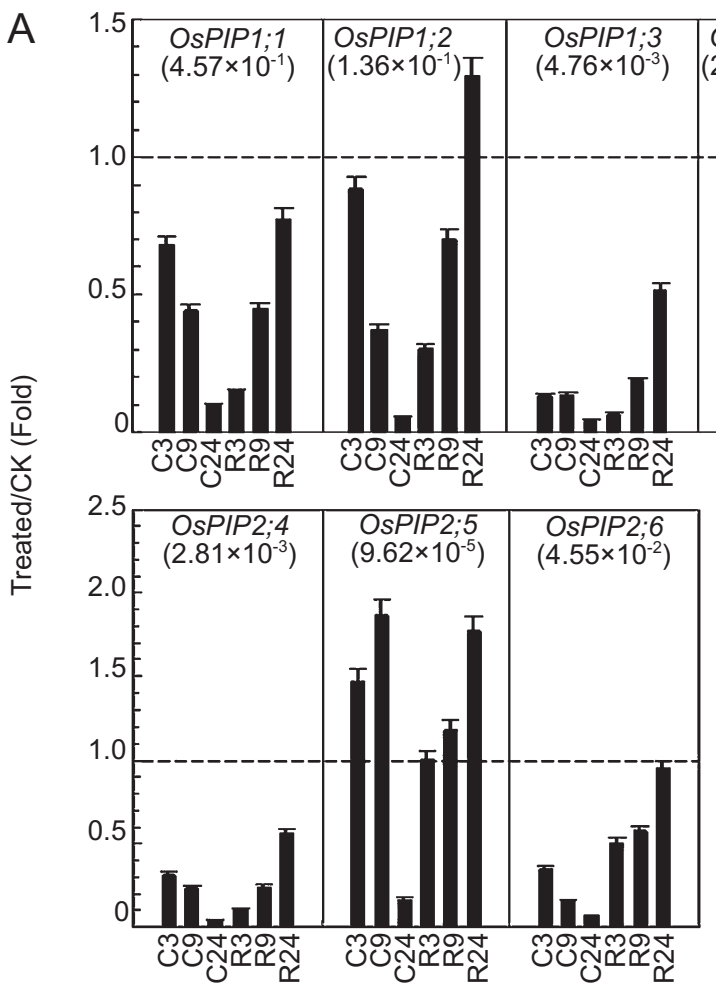

B

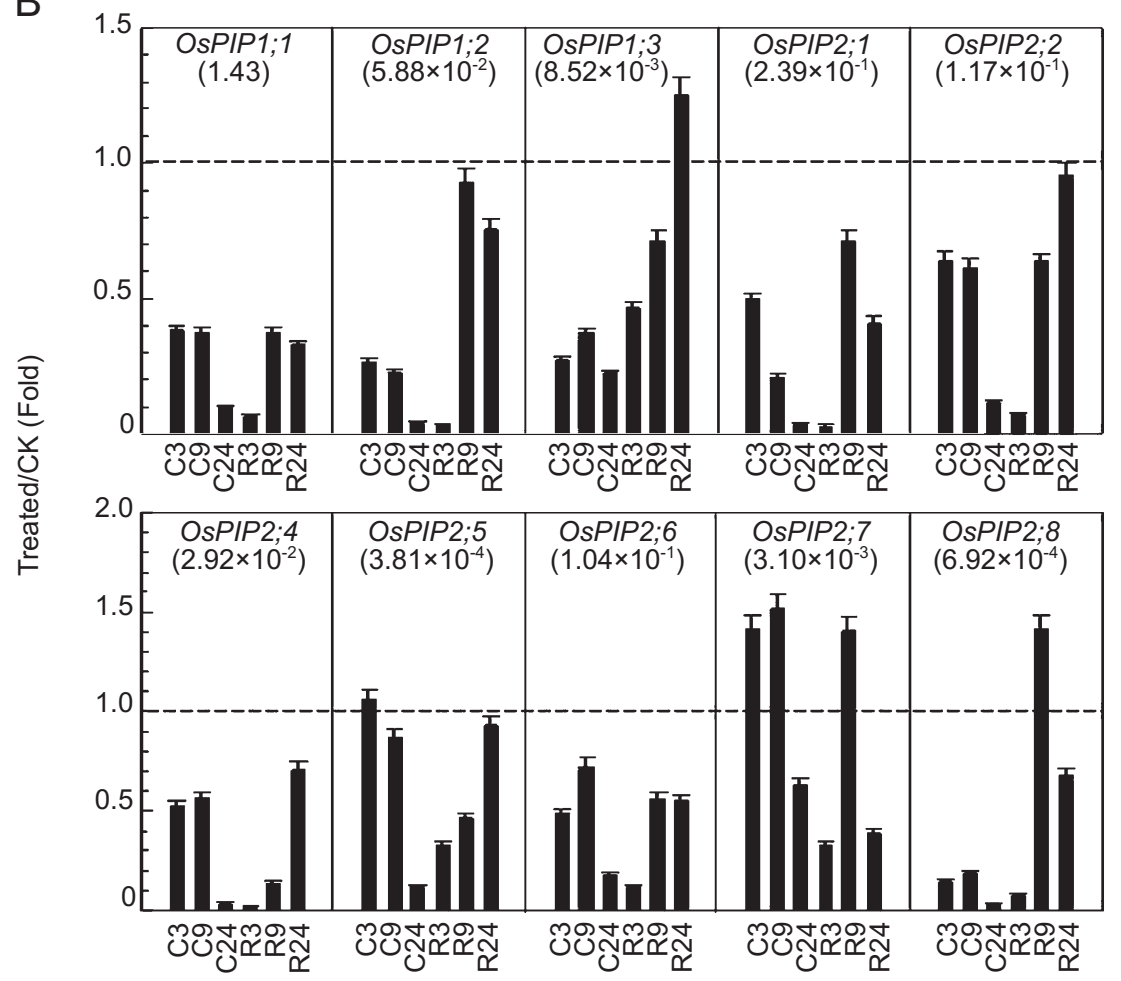

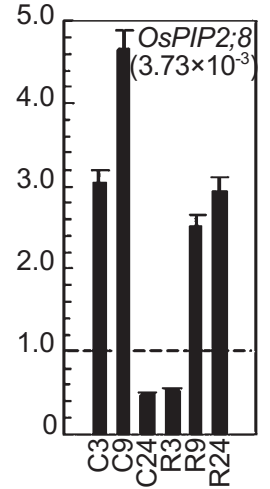

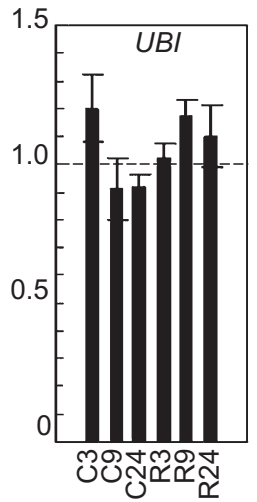

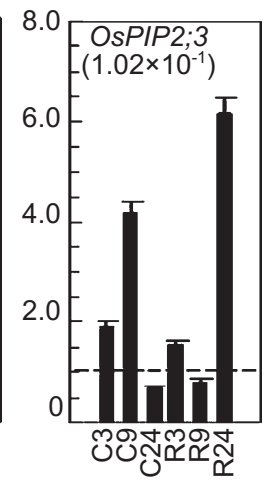

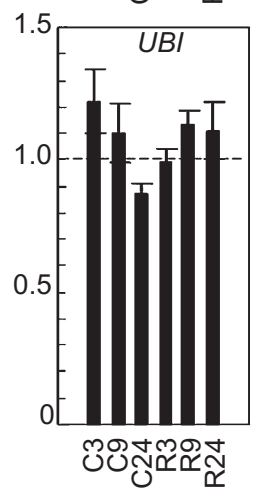

Figure 3 Expression profile of the 11 PIP genes in rice var. Nipponbare chilled at $7^{\circ} \mathrm{C}$ for $3(\mathrm{C} 3), 9(\mathrm{C} 9)$ and $24 \mathrm{~h}(\mathrm{C} 24)$ and after recovery at $28^{\circ} \mathrm{C}$ for 3 (R3), 9 (R9) and $24 \mathrm{~h}$ (R24). To allow for fluctuation of PIP expression under normal conditions, the relative expression of PIPs in the shoots (A) and roots (B) are described as Treated/Control ratio (fold). The PIP expression in chill-treated samples was taken at the same time point in time as the non-stressed control samples. Numbers in parentheses are the average values for each $P I P$ transcript levels $(P I P / U B I)$ at 12 time points evenly distributed in a $24 \mathrm{~h}$ cycle under non-stressed condition. The relative expression of $U B I$ described by Treated/Control (fold) is also shown as a reference. Values are means \pm S.D. of 3 replicates. 


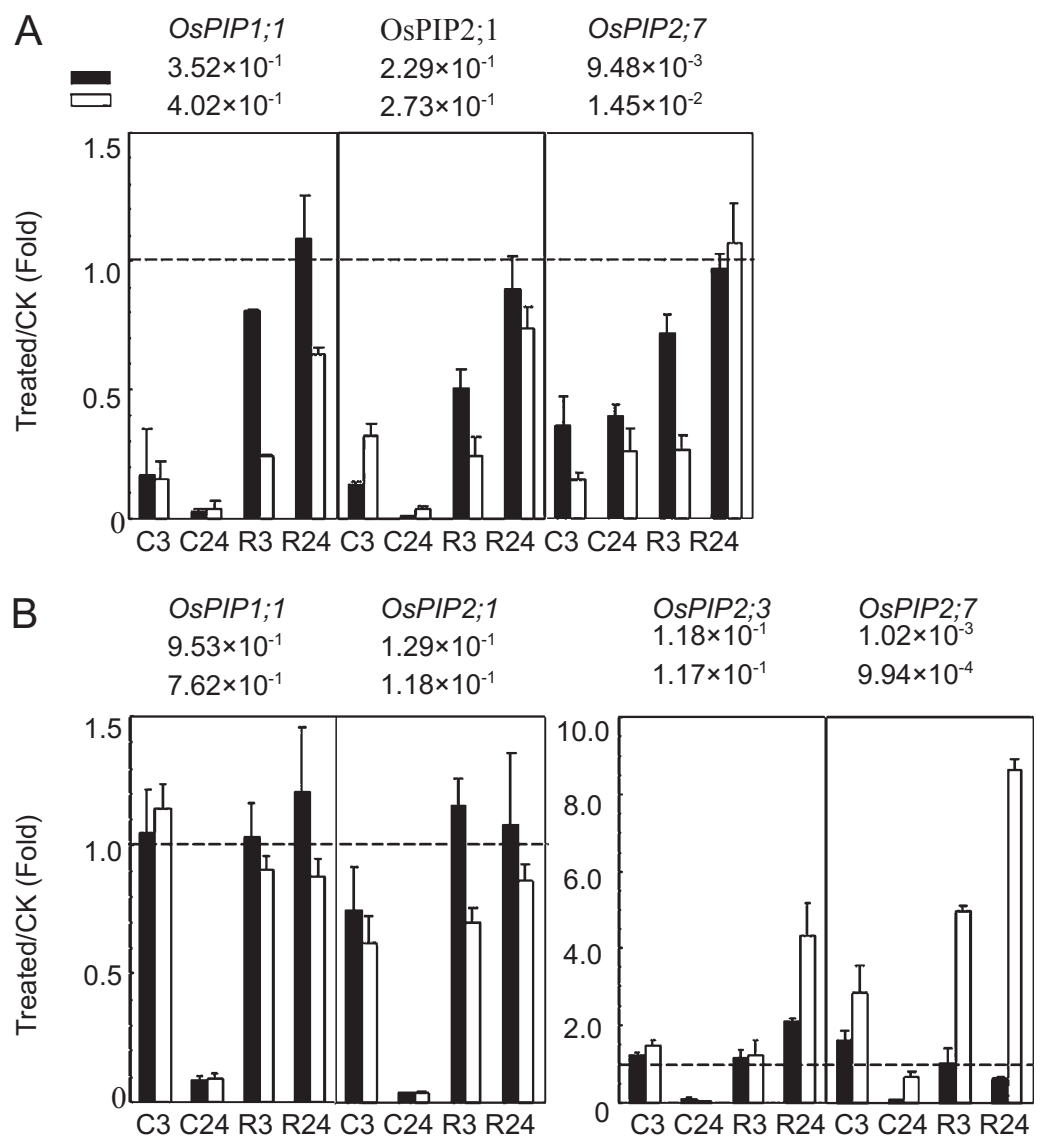

Figure 4 Expression of PIP genes in Somewake (black column) and Wasetoitsue (white column). The plants were chilled at $7{ }^{\circ} \mathrm{C}$ for $3(\mathrm{C} 3)$ and $24 \mathrm{~h}(\mathrm{C} 24)$ then allowed to recover at $28^{\circ} \mathrm{C}$ for 3 (R3) and $24 \mathrm{~h}(\mathrm{R} 24)$. To allow for fluctuation of PIP expression under normal conditions, the relative expression of PIPS in the shoots (A) and roots (B) were compared to the concurrent controls. Values are means \pm S.D. of 3 replicates. The average values for each $P I P$ transcript levels compared to $U B I(P I P / U B I)$ at the time point corresponding to C3, C24, R3 and R24 under non-stressed condition are also shown. Black bars, Somewake; white bars, Wasetoitsue.

and roots, followed by a recovery upon return to optimum temperature. The exceptions to this general pattern were OsPIP 2;5 and OsPIP 2;8 in shoots, OsPIP 2;3 and OsPIP $2 ; 7$ in roots, which were enhanced during the early stage of chilling, but decreased after $24 \mathrm{~h}$ of chilling. During the recovery, it was noted that expression of OsPIP $2 ; 8$ in shoots and $O_{S} P I P 2 ; 3$ in roots increased as much as 3 and 6 fold, respectively. This might reflect overcompensation for the sharp drop in water transport resulting from the chilling treatment. Most PIPs had similar expression patterns during the chilling and recovery, yet distinct features were exhibited among different PIP isoforms and plant tissues (shoots or roots) when the timing and scope of changes was considered in detail.

The PIP gene expression in Wasetoitsu and Somewake during chilling and recovery

In order to gain insight into the role of PIPs in chilling tolerance, the expression of OsPIP1;1, OsPIP2;1, Os$P I P 2 ; 3$ and $O S P I P 2 ; 7$ by Somewake and Wasetoitsu was compared during chilling and recovery. In both Somewake and Wasetoitsu, the relative expression of OsPIP1;1, OsPIP 2; 1, OsPIP 2;3 and OsPIP2;7 in shoots and OsPIP1;1 and $O S P I P 2 ; 1$ in roots decreased significantly when the plants were chilled for $24 \mathrm{~h}$, but increased when returned to $28{ }^{\circ} \mathrm{C}$. OSPIP 2;3 and OSPIP 2;7 were induced early in the chilling period but their expression was reduced after $24 \mathrm{~h}$ of chilling. During the recovery, Somewake had larger increases in relative expression of OSPIP $1 ; 1, O S P I P 2 ; 1$ and OsPIP 2; 7 in shoots, and $O S P I P 1 ; 1$ and $O S P I P 2 ; 1$ in roots than Wasetoitsu. Interestingly, the relative expression of OsPIP 2:3 and OsPIP 2; 7 in roots increased 4 and 8 fold, respectively in Wasetoitsu after $24 \mathrm{~h}$ of recovery, whereas this surprising overexpression of PIPS was not observed in Somewake (Figure 4).

In addition, Western blots were used to analyze the 


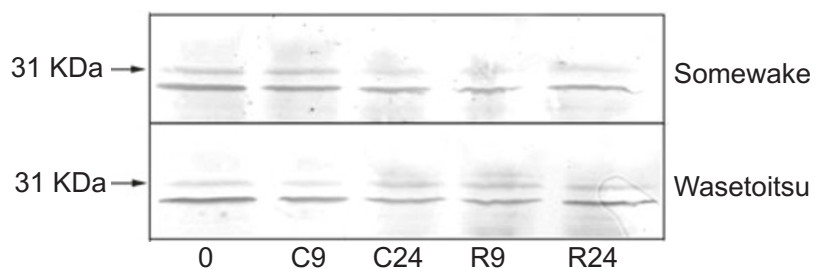

Figure 5 Western blot analysis of the PIP1 protein expression in roots of Wasetoitsue and Somewake. The plants were chilled at $7{ }^{\circ} \mathrm{C}$ for 9 (C9) and $24 \mathrm{~h}(\mathrm{C} 24)$ and then allowed to recover at $28^{\circ} \mathrm{C}$ for 9 (R9) and $24 \mathrm{~h}$ (R24). Plasma membrane protein $(20 \mu \mathrm{g})$ was loaded in each lane. Rabbit serum raised against N-terminal conservative peptide (KDY NEP PPA PLF EPG ELS SWS) of PIP conjugated to BSA was used as the primary antibody $(1: 500)$ and anti-rabbit $\operatorname{IgG}(1: 1,000)$ conjugated to alkaline phosphatase was used as the secondary antibody. The signals were visualized by NBT/BICP substrates.

changes of PIP protein abundance in roots of Somewake and Wasetoitsu during chilling and recovery. Figure 5 shows the results of a Western blot analysis using purified antibody raised against a conserved $\mathrm{N}$-terminal peptide of PIPs (See Material and Methods). Two bands of approximately $30 \mathrm{kDa}$ reacted with the PIP antibody. Both were considered to be PIP proteins but probably differed in their posttranslational modification [35]. PIP protein abundance slightly decreased during chilling and recovered to approximately the initial value after warming to $28^{\circ} \mathrm{C}$ in both varieties. No difference of PIP protein abundance in roots of Somewake and Wasetoitsu was observed.

\section{Discussion}

In this research, the effects of chilling on water relations in two rice varieties differing in chilling tolerance were analyzed. The chilling-tolerant variety, Somewake had slightly impaired water status and osmotic root Lp during chilling and recovery. We determined the integrated expression profile of the PIP gene family in the rice var. Nipponbare. Moreover, in order to investigate the relationship between PIP aquaporins and plant chilling tolerance, we compared the expression of 4 PIPs (3 functional water channel proteins and a root-specific PIP) in Somewake and Wasetoitsu, a chilling sensitive variety during chilling and recovery.

A large number of reports have centered on root water uptake of plants subjected to chilling stress. In this study, chilling led to a dramatic decrease in osmotic root Lp in Somewake and Wasetoitsu (Figure 2C), an observation that paralleled observations in maize $[3,6]$, spinach [9], bean [8], cucumber and figleaf gourd [12]. The water imbalance was probably triggered by the sharp drop in root water uptake at the onset of chilling, whereas decreased transpira- tion occurred later (Figure 2B). The chilling-induced water deficit was reflected in low leaf RWC (Figure 2A).

In figleaf gourd [12] and chilling tolerant maize [3, 4], long-term chilling treatment resulted in an even larger root Lp than unchilled control plants. This overcompensation in root water transport may be a type of cold acclimation in chilling tolerant plants. No overcompensation in osmotic root Lp occurred in Somewake and Wasetoitsu, but a very slight increase in Lp was observed in Somewake after 24 $\mathrm{h}$ of chilling (Figure 2C). Insufficient duration (24 h) of low temperature possibly explains this inconsistency with the other species, as the overcompensation in figleaf gourd occurred only after $6 \mathrm{~d}$ of $8{ }^{\circ} \mathrm{C}$ [12].

Aquaporins, which facilitate water flux across membranes, belong to a highly conserved MIP family, and play an essential role in maintaining water homeostasis under conditions that require adjustments in water flux. At the mRNA level, decreased expression of individual PIP genes during chilling was observed in rice [19, 7], maize [6] and Arabidopsis [20]. We determined the expression of all the 11 PIP genes by real-time RT-PCR using TaqMan-MGB probes, and found that chilling reduced the expression of most PIP genes in our experiments (Figure 3), a result consistent with a previous report [7]. However, our data showed wider changes in expression of PIPs, explained by the more sensitive method and detailed time scale we used to detect gene expression. The decreased relative expression of 4 PIP genes (Figure 4) and the low PIP protein content (Figure 5) were in line with the reduction in osmotic root $\mathrm{Lp}$ in Somewake and Wasetoitsu during chilling (Figure 2C). Water channel proteins are known to allow bi-directional water movement along the water potential gradient. The result suggested that lower aquaporin expression and water transport facilitates achieving appropriate water status at low temperature.

Some of our results indicated that water channel activity was not controlled exclusively by PIP expression level or protein amount, and additional mechanisms were involved in this process. Results supporting this include the fact that the relative expression of some PIP genes was not always parallel to the changes in root Lp; that Western blots showed little difference between PIP protein abundance in Wasetoitsu and Somewake during the recovery (Figure 5), even though Lp were clearly different (Figure 2C); and that, the changes in total PIP protein abundance were not always consistent with the transcript expression level of individual PIP isoforms as described previously [36]. This idea is also supported by the results in Figure 5 that suggest posttranscriptional actions regulate PIP protein. A very recent review by Luu and Maurel [35] summarized possible mechanisms that may regulate water channel activities under various stress conditions including aquaporin 
subcellular localization, phosphorylation, cytosolic $\mathrm{pH}$, reactive oxygen, etc. How plants integrate these mechanisms in response to chilling is a challenge for future research.

Several reports suggested that aquaporins were necessary for chilling responses $[4,6]$, but the roles of aquaporins in chilling tolerance was still elusive. PIP genes did not exhibit a uniform expression pattern (Figure 3 and Figure 4), suggesting that PIPs did not respond in a simple uniform way but have more complex roles in influencing plant water balance during chilling. In support of this, the relative expression of OsPIP 1;1, OsPIP 2; 1, OsPIP 2;3 and OsPIP 2;7 generally decreased during chilling in the two varieties, indicating that these PIPs might not be the key factors for the early stage of rice chilling tolerance. In addition, the chilling tolerant variety, Somewake, had a higher relative expression of OSPIP1;1 (in shoots and roots), OSPIP2; 1 (in shoots and roots) and OSPIP 2; 7 (in shoots) than Wasetoitsu during the recovery, suggesting these PIPs were probably involved in re-establishment of the disturbed water balance. Wasetoitsu, in contrast, exhibited significant increases in the relative expression of $O S P I P 2 ; 3$ and $O S P I P 2 ; 7$ in roots. Wasetoitsu was severely injured when subjected to chilling $\left(7^{\circ} \mathrm{C}\right.$ ) for $24 \mathrm{~h}$ (Figure 1), so it seems reasonable to suggest that high expression of OSPIP2;3 and OSPIP2;7 in roots might overcompensate for the severe chilling-induced water deficit. Taken together, aquaporins probably play complex and diversified roles in plant chilling tolerance response depending on the aquaporin isoforms, the plant tissues and the stage of chilling duration.

\section{Acknowledgments}

We thank Prof. Yoshichika Kitagawa (Akita Prefectural University, Japan) for kindly providing the Wasetoitsu and Somewake rice seeds and for reviewing the manuscript. We also thank Dr Weining Sun for her technical assistance and review of the manuscript, and Dr David Lane for help with revision. This work was supported by the Key Basic Research Special Fund of CAS (KSCXZ-SW-116).

\section{References}

1 Thomashow MF. So what's new in the field of plant cold acclimation? lots! Plant Physiol 2001; 125:89-93.

2 Sanders P, Markhart AH. Root system functions during chilling temperatures: injury and acclimation. In: Basra S, eds. Crop responses and adaptations to temperature stress. Haworth Press: New York 2001:77-108

3 Perez de Juan J., Irigoyen JJ, Sanchez-Diaz M. Chilling of drought-hardened and non-hardened plants of different chilling-sensitive maize lines Changes in water relations and ABA contents. Plant Sci 1997; 122:71-79.

4 Aroca R, Tognoni F, Irigoyen JJ, Sanchez-Diaz M, Pardossi A.
Different root low temperature response of two maize genotypes differing in chilling sensitivity. Plant Physiol Biochem 2001; 39:1067-1073.

5 Melkonian J, Yu LX, Setter TL. Chilling responses of maize (Zea mays L.) seedlings: root hydraulic conductance, abscisic acid, and stomatal conductance. J Exp Bot 2004; 55:1751-1760.

6 Aroca R, Amodeo G., Fernandez-Illescas S, et al. The role of aquaporins and membrane damage in chilling and hydrogen peroxide induced changes in the hydraulic conductance of maize roots. Plant Physiol 2005; 137:341-353.

7 Sakurai J, Ishikawa F, Yamaguchi T, Uemura M, Maeshima M. Identification of 33 Rice Aquaporin genes and analysis of their expression and function. Plant Cell Physiol 2005; 46:15681577.

8 Vernieri P, Lenzi A, Figaro M, Tognoni F, Pardossi A. How the roots contribute to the ability of Phaseolus vulgaris L. to cope with chilling-induced water stress. J Exp Bot 2001; 52:21992206.

9 Fennell A, Markhart AH. Rapid acclimation of root hydraulic conductivity to low temperature. J Exp Bot 1998; 49:879-894.

10 Wan X, Zwiazek JJ, Lieffers VJ, Landhausser SM. Hydraulic conductance in aspen (Populus tremuloides) seedlings exposed to low root temperatures. Tree Phyiol 2000; 21:691-696.

11 Lee SH, Singh AP, Chung GC, et al. Exposure of roots of cucumber (Cucumis sativus) to low temperature severely reduces root pressure, hydraulic conductivity and active transport of nutrients. Physiol Plant 2004; 120:413-420.

12 Lee SH, Chung GC, Steudle E. Gating of aquaporins by low temperature in roots of chilling-sensitive cucumber and chilling-tolerant figleaf gourd. J Exp Bot 2005; 56:985-995.

13 Javot H, Maurel C. The role of aquaporins in root water uptake. Ann Bot (Lond) 2002; 90:301-313.

14 Maurel C, Javot H, Lauvergeat V, et al. Molecular physiology of aquaporins in plants. Int Rev Cytol 2002; 215:105-148.

15 Maurel C, Chrispeels MJ. Aquaporins. A molecular entry into plant water relations. Plant Physiol 2001; 125:135-138.

16 Tyerman SD, Niemietz CM, Bramley H. Plant aquaporins: multifunctional water and solute channels with expanding roles. Plant Cell Environ 2002; 25:173-194.

17 Steudle E. Water uptake by roots: effects of water deficit. J Exp Bot 2000; 51:1531-1542.

18 Steudle E, Peterson C. How does water get through roots? J Exp Bot 1998; 49:775-788.

19 Li L, Li S, Tao Y, Kitagawa Y. Molecular cloning of a novel water channel from rice: its products expression in Xenopus oocytes and involvement in chilling tolerance. Plant Sci 2000; 154:43-51

20 Jang JY, Kim DG, Kim YO, Kim JS, Kang H. An expression analysis of a gene family encoding plasma membrane aquaporins in response to abiotic stresses in Arabidopsis thaliana. Plant Mol Biol 2004; 54:713-725.

21 Maurel C. Aquaporins and water permeability of plant membranes. Annu Rev Plant Physiol Plant Mol Biol 1997; 48:399429.

22 Tyerman SD, Bohnert HJ, Maurel C, Steudle E, Smith JAC. Plant aquaporins: their molecular biology, biophysics and significance for plant water relations. J Exp Bot 1999; 50:1055-1071.

23 Quigley F, Rosenberg JM, Shachar-Hill Y, Bohnert HJ. From genome to function: the Arabidopsis aquaporins. Genome Biol 2002; 3:Research 0001. Epub 1-7. 
24 Chaumont F, Barrieu F, Wojcik E, Chrispeels MJ, Jung R. Aquaporins constitute a large and highly divergent protein family in maize. Plant Physiol 2001; 125:1206-1215.

25 Gachon C, Mingam A, Charrier B. Real-time PCR: what relevance to plant studies? J Exp Bot 2004; 55:1445-1454.

26 Ni JS. Solution culture of rice. In: Xue YL, eds. Experiment Handbook of Plant Physiology. Shanghai, China. 1985:63-65 (in Chinese)

27 Lian HL, Yu X, Ye Q, et al. The role of aquaporin RWC3 in drought avoidance in rice. Plant Cell Physiol 2004; 45:481489.

28 Miyamoto N, Steudle E, Hirasawa T, Lafitte R. Hydraulic conductivity of rice roots. J Exp Bot 2001; 52:1835-1846.

29 Martinez-Ballesta MC, Aparicio F, Pallas V, Martinez V, Carvajal $\mathrm{M}$. Influence of saline stress on root hydraulic conductance and PIP expression in Arabidopsis. J Plant Physiol 2003; 160:689-697.

30 Nishi R, Hashimoto H, Kidou S, Uchimiya H, Kato A. Isolation and characterization of a rice cDNA which encodes a ubiquitin protein and a 52 amino acid extension protein. Plant Mol Biol 1993; 22:159-161.

31 Ohshima Y, Iwasaki I, Suga S, Murakami M, Inoue K. Maeshima
M. Low aquaporin content and low osmotic water permeability of the plasma and vacuolar membranes of a CAM plant Graptopetalum paraguayense: comparison with radish. Plant Cell Physiol 2001; 42:1119-1129.

32 Bradford MM. A rapid and sensitive for the quantitation of microgram quantities of protein utilizing the principle of protein-dye binding. Anal Biochem 1976; 72:248-254.

33 Sambrook F, Fritsch EF, Maniatis T. Molecular Cloning: A Laboratory Manual. 2nd edn. Cold Spring Harbor, New York 1989:1860-1865.

34 Kitagawa Y, Yoshizaki K. Water stress-induced chilling tolerance in rice; putative relationship between chilling tolerance and $\mathrm{Ca}^{2+}$ flux. Plant Sci 1998; 137:73-85.

35 Luu DT, Maurel C. Aquaporins in a challenging environment: molecular gears for adjusting plant water status. Plant Cell Environ 2005; 28:85-96.

36 Suga S, Murai M, Kuwagata T, Maeshima M. Differences in aquaporin levels among cell types of radish and measurement of osmotic water permeability of individual protoplasts. Plant Cell Physiol 2003; 44:277-286.

Edited by Bernd Mueller-Roeber 